\title{
Feasibility of Increasing the Slaughter Weight of Finishing Pigs
}

\author{
Byung-Chul Park ${ }^{2}$ and C. Young Lee ${ }^{1 *}$ \\ ${ }^{1}$ Regional Animal Industry Center, Gyeongnam National University of Science and Technology, Jinju 660-758, Korea and \\ ${ }^{2}$ Sunjin Co., Ltd, 517-3 Doonchon-dong, Kangdong-gu, Seoul 134-060, Korea
}

\begin{abstract}
The present review was aimed to assess the feasibility of increasing the slaughter weight(SW) of finishing pigs. Growth performance, including ADG, ADFI and gain:feed, does not change significantly with increasing SW between 110 and $135 \pm 5 \mathrm{~kg}$ in lean-genotype pigs, whereas in non-lean pigs, ADG and gain:feed decrease with increasing $\mathrm{SW}$ within the similar range of BW. Backfat thickness (BFT) and marbling of the carcass, which are greater in barrows than in gilts, increase with the increase of SW. The SW could be increased by using a low-energy diet and thereby reducing the rate of fat deposition per weight gain. The yield of the belly increases with the increase of SW, which may be economically significant in Korea. However, yields of some other primal cuts do not change so much as to affect the carcass value. The redness and fat content of the muscle increase slightly with the increase of SW whereas moisture content is minimally influenced by SW. Muscular protein content rarely changes, but sometimes increases slightly, with increasing SW. Other physicochemical characteristics, including lightness, pH, drip loss, and cooking loss of the muscle, are barely influenced by SW. Marbling of fresh loin and ham increases with increasing SW. Sensory characteristics of fresh loin, ham, and belly, including color, aroma, off-flavor, drip, and acceptability, are not influenced significantly by SW. The eating quality of cooked pork also has almost no relation to SW. In conclusion, it is thought that the current SW for moderately lean barrows and gilts can be raised up to 125 and $135 \mathrm{~kg}$, respectively, with BFT at these weights predicted to be approximately $24 \mathrm{~mm}$ near the last rib, without compromising the meat quality.
\end{abstract}

(Key words : Finishing pig, Growth, Slaughter weight, Carcass, Meat quality)

\section{INTRODUCTION}

The slaughter weight (SW) of finishing pigs is an important economic variable which affects not only the meat quality but also the profitability of pig production (Kim et al., 2005; Bonneau and Lebret, 2010). In general, it is beneficial to the producer to increase SW because following the increase of $\mathrm{SW}$, total number of animals required to produce a given weight of pork is reduced, normally accompanied by a reduced production cost. However, an increase of SW beyond a certain limit results in excessive fat deposition and the ensuing decrease in growth efficiency and carcass quality. Most modern pigs are therefore have been bred so leanly that the high lean gain potential of early finishing pigs does not decrease significantly up to SW which is now much greater than was possible a few decades ago.

The pig SW is influenced by a number of extrinsic factors as well. First of all, the consumers' preference for the fat content of pork influences SW to a most significant extent.
In this regard, finishing pigs may well be slaughtered at higher BW in countries including Korea where the fatness of the carcass or primal cuts favored by the consumers is relatively high. However, the average SW in Korea is lower than those in the USA and some European countries where lean pork is preferred (DARD, 2002; MLC, 2003; Kim et al., 2009; Table 1). The SW is also influenced by traditional as well as cultural backgrounds. For instance, in Hawaii where a high percentage of pig carcasses are used for barbecuing, the average SW is only approximately $90 \mathrm{~kg}$ (NASS, 2006) whereas in some Mediterranean regions where dry-cured ham and other pork products requiring large carcasses are produced, pigs are slaughtered at approximately $160 \mathrm{~kg}$ (Kim et al., 2005; Bonneau and Lebret, 2010). In addition, SW is widely variable depending on the carcass size that is desired by the butcher or packer, as is exemplified by the variations of average SW in the different states of the USA, which range approximately from 90 to $140 \mathrm{~kg}$ (NASS, 2006).

The corresponding author of this paper and his collaborators

* Corresponding author: C. Young Lee, Regional Animal Industry Center, Gyeongnam National University of Science and Technology, Jinju 660-758, Korea. Tel: 055-751-3285, Fax: 055-753-4422, E-mail: cylee@gntech.ac.kr 
Table 1. Average market weights of finishing pigs in selected countries in 2007 (from Kim et al., 2009)

\begin{tabular}{lc|lc}
\hline Country & $\begin{array}{c}\text { Market } \\
\text { Weight } \\
(\mathrm{kg})\end{array}$ & Country & $\begin{array}{c}\text { Market } \\
\text { Weight } \\
(\mathrm{kg})\end{array}$ \\
\hline \hline Denmark & 108.5 & Canada & 113.00 \\
Netherlands & 111.50 & U.K. & 98.80 \\
France & 115.80 & U.S.A. & 120.15 \\
Republic of Ireland & 98.40 & Japan & 114.00 \\
Germany & 120.00 & Korea & 111.1 \\
\hline
\end{tabular}

began the studies on the present topic with a review (Kim et al., 2005) covering the world trend of the pig market weight, the expected changes of the carcass and meat quality resulting from an increase of SW, and the nutritional and hormonal methods by which SW can be increased. This was followed by serial studies on various effects of increasing SW up to $138 \mathrm{~kg}$ (Lee et al., 2006, 2007; Park et al., 2007, 2009a,b). The main results of these studies have been pooled and analyzed in a previous study (Jeong et al., 2010) to render regressive relationships of SW to the variables associated with growth efficiency and physicochemical and sensory characteristics of major primal cuts.

The present study was undertaken to review the literature on the relationships between dietary energy level and growth efficiency of finishing pigs in association with their lean-gain potential and SW and thereby to assess the feasibility of increasing SW. The present review was also aimed to further analyze published results regarding the effects of SW of swine on their growth efficiency and physicochemical and sensory characteristics of fresh and cooked primal cuts of their resulting carcasses.

\section{RELATIONSHIPS BETWEEN SLAUGHTER WEIGHT AND PRODUCTION EFFICIENCY OF FINISHING PIGS}

\section{Growth efficiency}

The average daily gain (ADG) is usually greater in barrows than in gilts (Latorre et al., 2009; Table 2). The ADG barely changes with increasing SW between 110 and $135 \pm 5 \mathrm{~kg}$ in lean-genotype finishing pigs (Neely et al., 1979; Lee et al., 2006; Park et al., 2007, 2009b), although in a study of Latorre et al. (2008), ADG did not change up to $125 \mathrm{~kg}$ and declined thereafter. Furthermore, Cisneros et al. (1996) have reported that ADG of finishing pigs beginning from $60 \mathrm{~kg}$ had no relation to final BW between 100 and $160 \mathrm{~kg}$. Similarly, in the study of Corino et al. (2008), ADG between 114 and $161 \mathrm{~kg} \mathrm{BW}(1.06 \mathrm{~kg})$ was only marginally less than that between 78 and $111 \mathrm{~kg}(1.17 \mathrm{~kg})$. In non-lean pigs, however, a negative effect of increasing BW on ADG is evident even at above $100 \mathrm{~kg}$ (Kanis et al., 1990; Latorre et al., 2004, presented in Table 3).

The average daily feed intake (ADFI), which is greater in barrows than in gilts, usually increases slightly with increasing BW (Cisneros et al., 1996; Piao et al., 2004; Park et al., 2009b) up to approximately 135 to $140 \mathrm{~kg}$ irrespective of the genotype for lean gain, although there are incidences where ADFI was not influenced by SW (Latorre et al., 2004, 2008). In contrast to this, the gain:feed ratio is inconsistently influenced by sex and SW. The gain:feed ratio of gilts was superior to that of barrows in the studies of Leach et al. (1996) and Latorre et al. (2004 Table 3), but in Latorre et al. (2009) and others (Table 2), it did not differ between the two sexes. Moreover, the gain:feed ratio decreased slightly with increasing SW between 110 and $140 \mathrm{~kg}$ in some studies (Latorre et al., 2004, presented in Table 3; Piao et al., 2004; Park et al., 2009a), whereas in others (Cisneros et al., 1996; Leach et al., 1996; Park et al., 2007, 2009b), it was not influenced by SW within the similar range of SW. Dressing percentage usually neither differs between the barrow and gilt nor changes with increasing SW (Piao et al., 2004; Lee et al., 2006; Park et al., 2009a,b). However, sometimes, it is slightly greater in gilts than in barrows (Latorre et al., 2004; Lee et al., 2007; Park et al., 2007) and also slightly increases with the increase of SW (Cisneros et al., 1996; Latorre et al., 2008).

In summary, growth performance of lean-genotype pigs including the $\mathrm{ADG}$ and gain:feed ratio usually does not change significantly with the increase of SW up to approximately $140 \mathrm{~kg}$. In non-lean pigs, however, both ADG and gain:feed decrease with increasing SW above $100 \mathrm{~kg}$.

\section{Backfat thickness and slaughter weight}

Backfat thickness (BFT) is greater in barrows than in gilts, which is partly associated with the greater ADFI in the barrow (Tables 2 and 3). This variable also increases linearly with increasing BW, with a slope of 0.18 to $0.24 \mathrm{~mm} / \mathrm{kg}$, 
Table 2. Influences of slaughter weight (SW) on growth performance of lean-type finishing pigs ${ }^{1)}$

\begin{tabular}{|c|c|c|c|c|c|c|c|c|c|}
\hline \multirow[b]{2}{*}{ Item } & \multicolumn{2}{|c|}{ Gilt } & \multicolumn{2}{|c|}{ Barrow } & \multirow[b]{2}{*}{$\mathrm{SE}$} & \multirow{2}{*}{ Sig. ${ }^{a}$} & \multicolumn{3}{|c|}{ Regression on SW } \\
\hline & $\begin{array}{l}\text { Low } \\
\text { SW }\end{array}$ & $\begin{array}{c}\text { High } \\
\text { SW } \\
\end{array}$ & $\begin{array}{l}\text { Low } \\
\text { SW }\end{array}$ & $\begin{array}{c}\text { High } \\
\text { SW }\end{array}$ & & & Slope & SE & Sig. ${ }^{\mathrm{a}}$ \\
\hline Initial wt, kg & 85.8 & 87.0 & 86.2 & 86.9 & 0.6 & & - & - & - \\
\hline Final wt, kg & 109.2 & 132.0 & 110.2 & 127.3 & 0.6 & $\mathrm{~S}^{* *}, \mathrm{SW}^{* *}$ & - & - & - \\
\hline $\mathrm{ADG}, \mathrm{kg}$ & 0.79 & 0.84 & 0.89 & 0.89 & 0.02 & $\mathrm{~S}^{* *}$ & 0.003 & 0.0007 & $* *$ \\
\hline ADFI, kg & 3.12 & 3.45 & 3.33 & 3.52 & 0.05 & $\mathrm{~S}^{* *}, \mathrm{SW}^{* *}$ & 0.011 & 0.0022 & $* *$ \\
\hline Gain:feed & 0.238 & 0.236 & 0.249 & 0.241 & 0.005 & & 0.000 & 0.0002 & \\
\hline Backfat, mm & 18.4 & 23.3 & 20.8 & 24.2 & 0.4 & $\mathrm{~S}^{*}, \mathrm{SW}^{* *}$ & 0.217 & 0.0162 & $* *$ \\
\hline Carcass wt, kg & 81.4 & 99.9 & 81.6 & 95.5 & 0.5 & $\mathrm{~S}^{* *}, \mathrm{SW}^{* *}$ & 0.787 & 0.0110 & $* *$ \\
\hline Dressing, \% & 74.5 & 75.7 & 74.1 & 75.0 & 0.2 & $\mathrm{~S}^{*}, \mathrm{SW}^{* *}$ & 0.027 & 0.0081 & $* *$ \\
\hline
\end{tabular}

${ }^{1)}$ Pooled data from a total of 480 (Yorkshire $\times$ Landrace) $\times$ Duroc finishing pigs used in three published studies (Lee et al., 2006; Park et al., 2007, 2009b) were analyzed using GLM of SAS (1996). The model included the separate experiment corresponding to the 'plot' of a split-plot design and the interactions associated with it, in addition to sex, SW, sex $\times$ SW and the linear effect of SW, as fixed errors. The low SW for gilts and barrows was $110 \mathrm{~kg}$; the high SW were 130 to $138 \mathrm{~kg}$ for gilts and 125 or $130 \mathrm{~kg}$ for barrows, respectively. Backfat thickness is the average of the measurements between the $11^{\text {th }}$ and $12^{\text {th }}$ ribs and between the last rib and the $1^{\text {st }}$ lumbar. All animals received a diet containing $3.2 \mathrm{Mcal} \mathrm{DE} / \mathrm{kg}$. For brevity, effects of the separate experiment and the interactions associated with it are not indicated in this table.

${ }^{a} \mathrm{~S}$, sex; $* \mathrm{P}<0.05 ; * * \mathrm{P}<0.01$.

Table 3. Influences of slaughter weight on growth performance of non-lean finishing pigs ${ }^{1)}$

\begin{tabular}{|c|c|c|c|c|c|c|c|c|c|}
\hline \multirow{2}{*}{ Item } & \multicolumn{4}{|c|}{ Sex } & \multicolumn{5}{|c|}{ Slaughter weight $(\mathrm{kg})$} \\
\hline & Gilt & Barrow & SE & Sig. & 116 & 124 & 133 & SE & Sig. \\
\hline Initial wt, $\mathrm{kg}$ & 747.2 & 75.5 & 0.4 & F* & 74.9 & 74.7 & 74.8 & 0.4 & \\
\hline Final wt, $\mathrm{kg}$ & 120.9 & 128.5 & 1.1 & $* *$ & 116.2 & 124.4 & 133.5 & 1.3 & $* *$ \\
\hline $\mathrm{ADG}, \mathrm{kg}$ & 0.75 & 0.85 & 0.02 & $* *$ & 0.84 & 0.79 & 0.77 & 0.05 & $* *$ \\
\hline ADFI, kg & 2.45 & 2.84 & 0.05 & $* *$ & 2.69 & 2.56 & 2.68 & 0.06 & \\
\hline Gain:feed & 0.307 & 0.298 & 0.003 & $*$ & 0.313 & 0.309 & 0.287 & 0.003 & $* *$ \\
\hline Backfat, mm & 22.7 & 27.6 & 0.5 & $* *$ & 22.1 & 25.7 & 27.0 & 0.6 & $* *$ \\
\hline Carcass wt, $\mathrm{kg}$ & 94.7 & 99.5 & 0.8 & $* *$ & 89.8 & 96.4 & 105.1 & 1.0 & $* *$ \\
\hline Dressing, $\%$ & 78.3 & 77.4 & 0.2 & $* *$ & 77.3 & 77.7 & 78.6 & 0.2 & $* *$ \\
\hline
\end{tabular}

1) Data, which were adapted from Latorre et al. (2004), are the means of 96 non-lean (Landrace $\times$ Yorkshire $) \times($ Pietrain $\times$ Yorkshire $)$ finishing pigs. Backfat thickness was measured between the $3^{\text {rd }}$ and $4^{\text {th }}$ last ribs.

$* \mathrm{P}<0.05 ; * * \mathrm{P}<0.01$.

depending on the genotype, feeding program, or location of the back where the BFT is measured (Gu et al., 1992; Cisneros et al., 1996; Latorre et al., 2004; Jeong et al., 2010).

The maximal SW is limited by the fat content of the body represented by BFT which increases linearly with increasing SW (Gu et al., 1992). If consumers should allow BFT up to $24 \mathrm{~mm}$, the maximal SW for gilts and barrows assessed from the data presented in Table 2 are 135 and $126 \mathrm{~kg}$, respectively. Now that the present assessment has been made using data from animals which received a 'medium' energy-dense finisher diet containing 3.2 Mcal $\mathrm{DE} / \mathrm{kg}$, the suggested maximal SW may need to be reset downward if a producer uses a diet containing 3.4 Mcal $\mathrm{DE} / \mathrm{kg}$ recommended by NRC (1998) or a higher energy-dense diet. It also should be noted that in those countries where 
lean pork is preferred, restricted feeding or a low-energy diet may be needed to reach the suggested maximal SW without encountering with overfattening.

\section{Influence of dietary energy level on growth}

Upon increasing the dietary energy level between 2.9 and 3.5 Mcal DE/kg, ADG, gain:feed, and BFT usually increase while ADFI decreases (Chung et al., 1981; Chang and Chung, 1985; Lee et al., 2000, 2002). However, these effects of the dietary energy level are somewhat variable depending on the energy contents of the diets that are being compared. For instance, ADG and gain:feed were greater in leangenotype finishing pigs which had received the mediumenergy (3.2 Mcal DE/kg) vs 'low'-energy (3.0 Mcal DE/kg) diet (Park et al., 2009b), whereas in an earlier study (Lee et al., 2007), effects of a 'high'-(3.4 Mcal DE/kg) vs the medium-energy diet were non-significant in any of the growth variables including ADG and gain:feed (Table 4). Moreover, the effects of the low- vs medium-energy diet observed in the lean pigs were not significant in non-lean pigs in a later study (Ha et al., 2010).

Assuming that the BFT accretion rate of finishing pigs is $0.217 \mathrm{~mm} / \mathrm{kg}$ BW and that pigs on the low-energy diet (3.0
Mcal DE/kg) vs the control (3.2 Mcal DE/kg) have 1.8-mm less BFT at slaughter as presented in Tables 2 and 4, pigs on the low-energy diet will need to gain $8 \mathrm{~kg}$ more to reach the BFT of the animals which receive the control diet. In other words, the SW at a fixed target BFT will be $8 \mathrm{~kg}$ greater in those pigs fed the low-energy vs control diet. Although this appears to be somewhat of an overassessment, it seems quite feasible to increase SW to some extent by virtue of the BFT-reducing effect of the low-energy diet. The SW could also be increased by restricted feeding which is known to be useful for reducing fat deposition and for increasing the gain:feed ratio, especially in finishing barrows (Leymaster and Mersmann, 1991), but this method does not seem to be as useful as the use of the low-energy diet in terms of practical applicability.

These results suggest that SW of finishing pigs could be increased by providing them with a low-energy diet containing a $3.0 \mathrm{Mcal} \mathrm{DE} / \mathrm{kg}$ or less energy content vs a common diet containing 3.2 Mcal or greater DE per $\mathrm{kg}$ and thereby reducing the rate of fat deposition which limits the maximal SW. However, use of the low-energy diet will result in decreased ADG and gain:feed as well as decreased fat deposition.

Table 4. Effects of dietary energy level on growth performance of lean-type finishing pigs slaughtered at heavy weights

\begin{tabular}{|c|c|c|c|c|c|c|c|c|c|c|c|}
\hline \multirow{3}{*}{ Item } & \multicolumn{6}{|c|}{ Lee et al. (2007) } & \multicolumn{5}{|c|}{ Adapted from Park et al. (2009b) } \\
\hline & \multicolumn{2}{|c|}{ 3.4 Mcal DE/kg } & \multicolumn{2}{|c|}{ 3.2 Mcal DE/kg } & \multirow{2}{*}{$\mathrm{SE}$} & \multirow{2}{*}{ Sig. ${ }^{a}$} & \multicolumn{2}{|c|}{ 3.2 Mcal DE/kg } & \multicolumn{2}{|c|}{ 3.0 Mcal DE/kg } & \multirow{2}{*}{$\mathrm{SE}$} \\
\hline & Gilt & Barrow & Gilts & Barrow & & & Gilt & Barrow & Gilt & Barrow & \\
\hline Initial $\mathrm{wt}^{\mathrm{b}}, \mathrm{kg}$ & 93.0 & 89.7 & 93.6 & 90.2 & 0.9 & $\mathrm{~S}^{* *}$ & 79.9 & 79.9 & 79.9 & 80.4 & 0.9 \\
\hline Final $\mathrm{wt}^{\mathrm{b}}, \mathrm{kg}$ & 135.5 & 124.8 & 135.3 & 124.1 & 0.7 & $\mathrm{~S}^{*}$ & 135.0 & 125.6 & 138.5 & 127.9 & 0.8 \\
\hline $\mathrm{ADG}^{\mathrm{b}}, \mathrm{kg}$ & 0.80 & 0.75 & 0.82 & 0.79 & 0.02 & & 0.93 & 1.03 & 0.81 & 0.88 & 0.03 \\
\hline $\mathrm{ADFI}^{\mathrm{c}}, \mathrm{kg}$ & 2.94 & 2.90 & 2.91 & 3.03 & 0.10 & & 3.32 & 3.79 & 3.61 & 3.79 & 0.04 \\
\hline Gain:feed ${ }^{\mathrm{c}}$ & 0.268 & 0.255 & 0.274 & 0.254 & 0.008 & & 0.281 & 0.272 & 0.226 & 0.233 & 0.009 \\
\hline Backfat $^{\mathrm{b}, \mathrm{d}}, \mathrm{mm}$ & 24.3 & 24.0 & 22.4 & 24.7 & 0.6 & $\mathrm{~S} \times \mathrm{D}^{*}$ & 25.9 & 24.6 & 22.0 & 22.9 & 1.0 \\
\hline Carcass $\mathrm{wt}^{\mathrm{b}}, \mathrm{kg}$ & 102.3 & 92.9 & 101.3 & 92.6 & 0.6 & $\mathrm{~S}^{* *}$ & 102.3 & 94.3 & 105.1 & 95.2 & 1.1 \\
\hline Dressing $^{\mathrm{b}}, \%$ & 75.5 & 74.5 & 74.9 & 74.6 & 0.3 & $\mathrm{~S}^{*}$ & 75.8 & 75.0 & 75.9 & 74.4 & 0.8 \\
\hline
\end{tabular}

${ }^{\mathrm{a}} \mathrm{S}$, sex; D, diet.

${ }^{b}$ Data are the means of 40 and 16 animals in each diet $\times$ sex combination in Lee et al. (2007) and Park et al. (2009b), respectively.

${ }^{\mathrm{c}}$ Data are the means of four pens (replicates) in each diet $\times$ sex combination in both studies.

${ }^{\mathrm{d}}$ Adjusted for a 125-kg live weight for barrows in both studies, and for 135- and 138-kg live weights for gilts in the studies of Lee et al. (2007) and Park et al. (2009b), respectively.

$* \mathrm{P}<0.05 ; * * \mathrm{P}<0.01$. 


\section{INFLUENCES OF SLAUGHTER WEIGHT ON CARCASS GRADES AND PRIMAL YIELDS}

\section{Carcass weight and grading}

The carcass grading criteria in different countries are not only widely variable but are thought to be beyond the scope of present review. Accordingly, the current situation regarding the relationship between SW and the carcass grade in Korea will be introduced here as an example. Pig carcasses in Korea have been judged to A, B, C, or D of yield grade primarily according to BFT and carcass weight which should be between 80 and $94 \mathrm{~kg}$ to be eligible for grade $\mathrm{A}$, and between 76 and $98 \mathrm{~kg}$ to be eligible for grade B (MIFAFF, 2007). If the maximum carcass weights for grades $A$ and $B$ are converted to live weights by dividing them by 0.75 of the average dressing ratio, they are equal to 125 and $131 \mathrm{~kg}$ live weights, respectively, which are close to the 126 and $135 \mathrm{~kg}$ maximal SW suggested for the barrow and gilt, respectively, in the previous section. The average SW in Korea, however, is only $111 \mathrm{~kg}$ (Table 1) for the following reasons. Most packers discount the price for any carcass weighing $90 \mathrm{~kg}$ or greater ( $\geq 120 \mathrm{~kg}$ in live weight) regardless of the yield grade to assure the size uniformities of their wholesale cuts. What is more, they try to safeguard the quality of the belly, the most preferred and expensive cut in this country, by penalizing the larger carcasses and thereby minimizing the chance of 'adulterating' their wholesale packs with what they call the "caky-fat" belly which is found in some of the fat carcasses exhibiting a $30 \mathrm{~mm}$ or greater BFT. Consequently, many pig producers do not dare to increase the pig market weights to the maximum for fear of the oversize penalty, which results in the average SW being lower than is desirable. Therefore, to be fair to the producers, it is thought to be necessary to raise the maximum carcass weights for good grades accepted by the packer as well as for yield grades A and B.

\section{Carcass quality}

The BFT and marbling score are probably the most representative carcass grading criteria throughout the world. These two carcass quality variables, which are greater in barrows than in gilts, are correlated although the coefficient is not significant in gilts (Table 5). Moreover, in the study of Park et al. (2009b), marbling at $138 \mathrm{~kg}$ of live weight increased when a 9-week finishing period on the control diet (3.2 Mcal DE/ $\mathrm{kg}$ ) was extended by approximately one week by using the low-energy $\operatorname{diet}(3.0 \mathrm{Mcal} \mathrm{DE} / \mathrm{kg})$. This is consistent with the notion that marbling increases not only with adipose tissue growth but also with age (Huff-Lonergan et al., 2003). Interestingly, carcass quality grade was highly correlated with marbling as well as with BFT to some extent when the grade was quantified. Marbling therefore appears to

Table 5. Backfat thickness (BFT), marbling grade (MG), and quality grade (QG) of pig carcasses: effects of sex and Pearson's correlations between liveweight (LW), BFT, MG, and $\mathrm{QG}^{1)}$

\begin{tabular}{|c|c|c|c|c|c|c|c|c|c|c|c|c|}
\hline \multirow{3}{*}{ Item } & \multicolumn{3}{|c|}{ Mean \pm SD } & \multicolumn{9}{|c|}{ Pearson's correlation coefficient with the corresponding variable } \\
\hline & \multirow{2}{*}{$\begin{array}{c}\text { Gilts } \\
(n=168)\end{array}$} & \multirow{2}{*}{$\begin{array}{c}\text { Barrows } \\
(\mathrm{n}=168)\end{array}$} & \multirow{2}{*}{ Sig. } & \multicolumn{3}{|c|}{ Within Gilts } & \multicolumn{3}{|c|}{ Within Barrows } & \multicolumn{3}{|c|}{ Gilts + Barrows } \\
\hline & & & & BFT & MG & QG & BFT & MG & QG & BFT & MG & QG \\
\hline $\mathrm{LW}, \mathrm{kg}$ & $120.3 \pm 10.7$ & $120.7 \pm 12.0$ & & $0.48 * *$ & 0.02 & 0.04 & $0.26 * *$ & -0.06 & 0.03 & $0.34 * *$ & -0.02 & 0.04 \\
\hline $\mathrm{BFT}, \mathrm{mm}$ & $21.1 \pm 4.1$ & $23.9 \pm 4.8$ & $* *$ & - & 0.05 & 0.05 & - & $0.24 * *$ & $0.18 *$ & - & $0.23 * *$ & $0.19 * *$ \\
\hline $\mathrm{MG}^{\mathrm{a}}$ & $1.74 \pm 0.63$ & $2.16 \pm 0.85$ & $* *$ & - & - & $0.64 * *$ & - & - & $0.70 * *$ & - & - & $0.69 * *$ \\
\hline $\mathrm{QG}^{\mathrm{b}}$ & $2.61 \pm 0.56$ & $2.90 \pm 0.58$ & $* *$ & - & - & - & - & - & - & - & - & - \\
\hline
\end{tabular}

\footnotetext{
${ }^{1)}$ Pooled data from three studies (Park et al., 2009b; Ha et al., 2010; unpublished results of C. Y. Lee et al.) were analyzed using GLM Procedure and CORR Procedure of SAS (1996). In the first study, a total of 192 pigs were slaughtered at 110, 125, or $138 \mathrm{~kg}$, with equal numbers of gilts and barrows assigned at each target weight; in the latter two studies, 72 gilts and 72 barrows in total were slaughtered approximately at $115 \mathrm{~kg}$. The GLM included the separate study and sex as well as their interaction, but for brevity, effects of the separate study and the interaction are not indicated in this table.

${ }^{a}$ No. 4 or 5 , No. 2 or 3 , and No. 1 of the MIFAFF (2007) standard corresponding to the quality grades $1^{+} \& 1,2$, and 3 were assigned 4, 2, and 1 points of an arbitrary grade unit, respectively.

budged according to the quality of the whole carcass including the meat color, texture, marbling, quality of fat including its color, and the quality of the belly which includes the absolute and relative thicknesses (balance) of the fat and muscle layers (MIFAFF, 2007). Grades $1^{+}, 1,2$, and 3 were assigned $4,3,2$, and 1 points of an arbitrary grade unit, respectively.

$* \mathrm{P}<0.05 ; * * \mathrm{P}<0.01$.
} 
be a most significant factor determining the quality grade of pig carcasses in Korea.

\section{Primal yield}

The yield percentage of total trimmed primal cuts per SW is usually greater in gilts than in barrows and also in the high-lean vs medium- or low-lean genotype due to a greater percentage of trimmed subcutaneous fat in the latter (Martin et al, 1980; Unruh et al., 1996; Park et al., 2007; Latorre et al., 2008; Table 6). However, published results on the effect of SW on this variable are inconsistent. Martin et al. (1980) and Corino et al. (2008) have reported that the primal yield percentage decreased with increasing SW, whereas in Neely et al. (1979) and Park et al. (2007), SW exerted no influence on this variable.

Yields of some primal cuts other than the belly are influenced by SW within such narrow ranges (Cisneros et al., 1996; Latorre et al., 2004, 2008; Jeong et al., 2010) as not to influence the carcass value. However, the yield of the belly increases by 0.35 to $0.5 \%$ per $10 \mathrm{~kg}$ increase of SW (Martin et al., 1980; Jeong et al., 2010).

In summary, marbling of finishing pigs can be enhanced by providing them with a low-energy diet and thereby extending the age at a pre-determined slaughter weight. The yield percentage of the belly increases linearly with increasing SW up to $140 \mathrm{~kg}$, which is considered to be economically significant in Korea. However, percent yields of some other primal cuts are minimally influenced by SW not only numerically but economically.

\section{PHYSICOCHEMICAL CHARACTERISCTICS OF THE MUSCLE}

\section{Physical attributes}

The size of all types of muscle fibers, i.e. Types I (red), IIB (white), and IIA (intermediate), in the loin increases with increasing SW of finishing pigs between 110 and $140 \mathrm{~kg}$ (Park, 2010). On the other hand, the density of these muscle fiber types per $\mathrm{mm}^{2}$ cross-section decreases almost proportionately (Ryu and Kim, 2005; Park, 2010).

The lightness [CIE (1978) $\left.\mathrm{L}^{*}\right]$ of the longissimus muscle (loin), ham, and belly neither differs between gilts and barrows nor changes with increasing SW to any significant extent (Corino et al., 2008; Jeonget al., 2010; Table 7). The redness $\left(a^{*}\right)$ of these cuts is not influenced by the gender. Instead, the $\mathrm{a}^{*}$ value, which reflects the muscular myoglobin

Table 6. Effects of slaughter weight (SW) on the yields of primal cuts of finishing pigs (adapted from Leach et al., 1996)

\begin{tabular}{|c|c|c|c|c|c|c|c|}
\hline \multirow{2}{*}{ Item } & \multirow{2}{*}{ Barrow $^{a}$} & \multirow{2}{*}{ Gilt $^{\mathrm{a}}$} & \multirow{2}{*}{$\mathrm{SE}$} & \multirow{2}{*}{ Sig. ${ }^{b}$} & \multicolumn{3}{|c|}{ Linear regression on $\mathrm{SW}$} \\
\hline & & & & & Slope & $\mathrm{SE}$ & Sig. ${ }^{\mathrm{b}}$ \\
\hline Live weight, $\mathrm{kg}$ & 121.8 & 121.5 & 0.51 & NS & - & - & - \\
\hline \multirow[t]{2}{*}{ Side wt (trimmed), kg } & 42.3 & 44.9 & 0.51 & $* * *$ & -0.097 & 0.0383 & $\mathrm{Bar}^{\mathrm{c}}$ \\
\hline & & & & & -0.000 & 0.0468 & Gilt $^{\mathrm{c}}$ \\
\hline \multicolumn{8}{|l|}{ Wholesale cut percentage } \\
\hline Ham & 25.4 & 26.7 & 0.24 & $* * *$ & -0.019 & 0.0159 & NS \\
\hline Loin & 26.7 & 26.1 & 0.31 & NS & -0.038 & 0.0200 & NS \\
\hline \multirow[t]{2}{*}{ Belly } & 16.0 & 15.4 & 0.32 & NS & -0.002 & 0.0272 & $\operatorname{Bar}^{\mathrm{c}}$ \\
\hline & & & & & 0.092 & 0.0237 & Gilt $^{\mathrm{c}}$ \\
\hline Spare ribs & 3.3 & 3.4 & 0.08 & NS & 0.005 & 0.0051 & NS \\
\hline Shoulder & 20.6 & 20.4 & 0.21 & NS & 0.008 & 0.0139 & NS \\
\hline Clear plate & 2.6 & 2.0 & 0.09 & $* * *$ & 0.004 & 0.0057 & NS \\
\hline Jowl & 3.4 & 3.4 & 0.13 & NS & 0.003 & 0.0087 & NS \\
\hline
\end{tabular}

${ }^{a}$ A total of 144 pigs were slaughtered at 110,125 , or $140 \mathrm{~kg}$, with equal numbers of gilts and barrows assigned at each live weight.

${ }^{\mathrm{b}} \mathrm{NS}$, non-significant; $* * * \mathrm{P}<0.001$.

${ }^{\mathrm{c}}$ Regressions differ $(\mathrm{P}<0.05)$ for barrow (Bar) and gilt. 
content, increases with the increase of SW (Latorre et al., 2004; Park et al., 2007) concomitantly with the developmental increase of the myoglobin content (Martin et al., 1980; Latorre et al., 2004 Corino et al., 2008). There are incidences, however, where an increase of the $a^{*}$ value associated with growth does not reach a statistical significance (Leach et al., 1996; Table 7).

The 24-h muscular $\mathrm{pH}$ does not change or slightly decreases with the increase of SW (Corino et al., 2008; Park et al., 2009a,b), with an exception of a slight increase of loin $\mathrm{pH}$ with the increase of SW in Park et al. (2009a). However, the change in $\mathrm{pH}$ unit associated with the increase of SW within a practical range is not large enough to increase the incidence of PSE (pale, soft, and exudative) which can be caused by low postmortem muscular $\mathrm{pH}$ (Cisneros et al., 1996).

Drip losses of the loin and ham are circumstantially influenced slightly by the sex or SW. However, the effects of the sex and SW on this attribute within the practical range are thought not to be significant enough to affect the incidence of PSE which also occurs at a 5\% or greater drip loss (Warner et al., 1997; Joo et al., 1999). Cooking losses of the lean cuts are quite variable among published results in terms of numerical measurements as well as with respect to the effects of the gender and SW (Latorre et al., 2004; Park et al., 2009b).

\section{Chemical composition}

The moisture content in the loin, ham and belly is minimally influenced by the gender or SW. Sometimes, the moisture content in these cuts neither differ between the two sexes nor changes with increasing SW, but at other times, it is slightly greater in gilts than in barrows and also increases slightly with increase of SW (Cinseros et al., 1996; Latorre et al., 2004, 2009; Fernandez-Duenas et al., 2008; Table 7).

Table 7. Physicochemical characteristics of the longissimus muscle of lean-type finishing pigs: effects of sex and regressions on slaughter weight (SW)

\begin{tabular}{|c|c|c|c|c|c|c|c|c|c|}
\hline \multirow{2}{*}{ Item } & \multicolumn{2}{|c|}{ Sex } & \multicolumn{2}{|c|}{ Target SW } & \multirow{2}{*}{$\mathrm{SE}$} & \multirow{2}{*}{ Sig. ${ }^{\text {a }}$} & \multicolumn{3}{|c|}{ Linear regression on $\mathrm{SW}$} \\
\hline & Gilt & Barrow & Low & High & & & Slope & SE & Sig. ${ }^{\text {a }}$ \\
\hline Live weight ${ }^{1)}$ & 120.2 & 118.5 & 109.2 & 129.5 & 0.9 & $\mathrm{~W}^{* *}$ & - & - & - \\
\hline \multicolumn{10}{|l|}{ Muscle color ${ }^{1)}$} \\
\hline CIE L* & 51.3 & 52.4 & 52.2 & 51.5 & 0.6 & & - & - & - \\
\hline CIE $a^{*}$ & 7.28 & 7.27 & 7.14 & 7.41 & 0.27 & & - & - & - \\
\hline \multicolumn{10}{|c|}{ Chemical composition $^{1)}, \%$} \\
\hline Moisture & 74.0 & 73.9 & 74.0 & 73.9 & 0.2 & & - & - & - \\
\hline Protein & 22.4 & 22.2 & 22.0 & 22.5 & 0.1 & $\mathrm{~W}^{* *}$ & - & - & - \\
\hline Live weight ${ }^{2}$ & 127.7 & 127.9 & - & - & 3.5 & & - & - & - \\
\hline $\mathrm{pH}-24 \mathrm{~h}^{2)}$ & 5.67 & 5.65 & - & - & 0.03 & & -0.002 & 0.0010 & $\mathrm{~S}$ \\
\hline Drip loss ${ }^{2)}, \%$ & 3.36 & 3.26 & - & - & 0.32 & & 0.029 & 0.0106 & $\mathrm{~S}$ \\
\hline Cooking loss ${ }^{2)}, \%$ & 23.36 & 23.35 & - & - & 0.70 & & 0.018 & 0.0229 & NS \\
\hline \multicolumn{10}{|c|}{ Chemical composition $^{2)}, \%$} \\
\hline Moisture & 73.14 & 72.85 & - & - & 0.16 & & -0.035 & 0.0053 & $\mathrm{~S}$ \\
\hline Fat & 3.26 & 3.70 & - & - & 0.19 & & 0.027 & 0.0061 & $\mathrm{~S}$ \\
\hline
\end{tabular}

${ }^{1)}$ Pooled data for a total of 152 loins derived from as many (Yorkshire $\times$ Landrace) $\times$ Duroc finishing pigs used in three published studies (Lee et al., 2006; Park et al., 2007, 2009b) were analyzed using GLM of SAS (1996). The model included the separate experiment corresponding to a 'plot' of a split-plot design and the interactions associated with it, in addition to sex, SW, sex $\times$ SW and the linear effect of SW, as fixed errors. The slaughter weights ranged from 110 to $138 \mathrm{~kg}$. For brevity, effects of the separate experiment and the interactions associated with it are not indicated in this table.

2) Data were adapted from the paper of Cisneros et al. (1996) in which 40 commercial hybrid and 40 (Yorkshire $\times$ Landrace) $\times$ Hampshire pigs were slaughtered at $100,115,130,145$, or $160 \mathrm{~kg}$.

${ }^{a} \mathrm{~W}$, target $\mathrm{SW} ;{ }^{* *} \mathrm{P}<0.01 ; \mathrm{S}$, significant $(\mathrm{P}<0.05)$; NS, non-significant $(\mathrm{P}>0.05)$. 
The protein content of the loin and ham is sometimes al., 2004; Wiseman et al., 2007; Park et al., 2009a,b; Table slightly greater in gilts than in barrows; at other times, 7). Muscular protein content usually is not affected significantly however, it does not differ between the two sexes (Latorre et by SW within a given genotype (Unruh et al., 1996; Latorre

Table 8. Sensory quality characteristics of fresh and cooked pig loin and belly: effects of sex and slaughter weight $(\mathrm{SW})^{1)}$

\begin{tabular}{|c|c|c|c|c|c|c|}
\hline \multirow[b]{2}{*}{ Item } & \multicolumn{3}{|c|}{ Gilt } & \multicolumn{3}{|c|}{ Barrow } \\
\hline & $\begin{array}{l}\text { Low } \\
\text { SW }\end{array}$ & $\begin{array}{l}\text { Medium } \\
\text { SW }\end{array}$ & $\begin{array}{l}\text { High } \\
\text { SW }\end{array}$ & $\begin{array}{l}\text { Low } \\
\text { SW }\end{array}$ & $\begin{array}{l}\text { Medium } \\
\text { SW }\end{array}$ & $\begin{array}{l}\text { High } \\
\text { SW }\end{array}$ \\
\hline
\end{tabular}

\begin{tabular}{|c|c|c|c|c|c|c|c|c|}
\hline Live wt, kg & 107.5 & 124.9 & 136.8 & 110.4 & 126.8 & 139.6 & 0.6 & $\mathrm{SW}^{* *}$ \\
\hline
\end{tabular}

Loin

$\begin{array}{llllllllll}\text { Color } & 5.59 & 5.94 & 5.60 & 5.52 & 5.82 & 5.45 & 0.24 & \\ \text { Aroma } & 3.14 & 3.09 & 3.13 & 3.23 & 3.19 & 2.98 & 0.10 & \\ \text { Off-flavor } & 2.54 & 2.36 & 2.29 & 2.46 & 2.33 & 2.42 & 0.07 & \mathrm{SW}^{*} \\ \text { Drip } & 5.12 & 5.20 & 5.25 & 5.41 & 4.90 & 4.97 & 0.20 & \\ \text { Marbling } & 3.70 & 4.74 & 4.70 & 4.31 & 5.07 & 5.28 & 0.36 & \mathrm{SW}^{*} \\ \text { Acceptability } & 4.99 & 5.36 & 5.30 & 5.23 & 5.45 & 5.46 & 0.16 & \end{array}$

Belly

\begin{tabular}{llllllllll} 
Color (fat) & 5.24 & 4.88 & 5.26 & 5.32 & 5.44 & 5.32 & 0.18 & \\
Color (muscle) & 5.38 & 5.69 & 5.90 & 5.68 & 5.67 & 5.98 & 0.16 & $\mathrm{SW}^{*}$ \\
Aroma & 3.54 & 3.71 & 3.74 & 3.74 & 3.73 & 3.79 & 0.10 & \\
Off-flavor & 1.87 & 1.31 & 0.76 & 0.77 & 1.35 & 1.42 & 0.32 & \\
Fat:lean ratio & 4.61 & 5.01 & 5.26 & 5.13 & 6.18 & 5.90 & 0.24 & $\mathrm{Sex}^{* *}, \mathrm{SW}^{* *}$ \\
Fat:lean balance & 4.82 & 5.39 & 5.06 & 5.17 & 5.00 & 5.05 & 0.15 & \\
Acceptability & 5.00 & 5.57 & 5.35 & 5.18 & 5.18 & 5.42 & 0.16 & \\
\hline
\end{tabular}

Loin

\begin{tabular}{llllllll} 
Color & 5.13 & 5.16 & 5.08 & 4.98 & 5.04 & 5.20 & 0.15 \\
Aroma & 3.54 & 3.59 & 3.72 & 3.69 & 3.66 & 3.69 & 0.11 \\
Off-flavor & 2.71 & 2.73 & 2.74 & 2.54 & 2.67 & 2.84 & 0.10 \\
Juiciness & 4.45 & 4.32 & 4.29 & 4.16 & 4.39 & 4.44 & 0.20 \\
Tenderness & 4.96 & 5.05 & 4.87 & 5.14 & 5.20 & 5.25 & 0.23 \\
Acceptability & 5.16 & 5.35 & 5.05 & 5.31 & 5.30 & 5.35 & 0.17 \\
Belly & & & & & & & \\
Aroma & 4.68 & 4.56 & 4.78 & 4.63 & 4.71 & 4.66 & 0.13 \\
Off-flavor & 2.47 & 2.48 & 2.52 & 2.48 & 2.51 & 2.51 & 0.09 \\
Juiciness & 5.43 & 5.37 & 5.48 & 5.51 & 5.46 & 5.53 & 0.11 \\
Tenderness & 5.50 & 5.67 & 5.71 & 5.63 & 5.86 & 5.51 & 0.15 \\
Taste & 5.85 & 5.65 & 5.81 & 5.62 & 5.70 & 5.85 & 0.14 \\
Acceptability & 5.50 & 5.53 & 5.62 & 5.60 & 5.63 & 5.53 & 0.13 \\
\hline
\end{tabular}

\footnotetext{
${ }^{1)}$ Data were adapted from a previous study (Park et al., 2009b). Quality traits were judged by sensory panelists according to a 9-point hedonic scale. Greater values indicate "darker," "stronger," "superior," and "greater" in color, aroma, fat:lean balance/acceptability, and fat:lean ratio/marbling, respectively. In off-flavor and drip, a greater value indicates "more" meaning "worse" in terms of quality. Data are means of 12 animals in each sex $\times$ SW combination.

$* \mathrm{P}<0.05 ; * * \mathrm{P}<0.01$.
} 
et al., 2004); however, the protein content in the loin sometimes increases with increasing $\mathrm{SW}$ in lean-type pigs (Piao et al., 2004; Table 7).

Fat contents of the loin and belly are greater in barrows than in gilts and normally increase with increasing SW (Jeong et al., 2010; Table 7), which is in line with the effects of the gender and SW on the fatness of the body. Moreover, Wiseman et al. (2007) and Schinckel et al. (2008) have reported that muscles of a high-lean genetic line (375 gm fat-free lean gain/day) had greater growth rates and greater contents of protein and moisture, lesser daily fat gain, and lesser fat content than those of a low-lean genetic line (280 gm fat-free lean gain/day). In the studies of the present author's team, the fat content of the ham was not influenced by sex or SW (Park et al., 2009a,b), whereas the composition of fatty acids of the loin was not consistent [Lee et al., 2006; Park et al., 2007; Park et al., 2009a,b (unreported therein)].

Collectively, the redness and fat content of the muscle increase slightly with the increase of SW. However, other physicochemical characteristics, as well as the histological characteristics, of the muscle do not change so much as to influence meat quality

\section{SENSORY QUALITY TRAITS OF FRESH AND COOKED MEAT}

\section{Fresh meat}

Meat color, aroma, off-flavor, and drip of fresh loin and ham judged by sensory panelists are uninfluenced or minimally influenced by sex or SW (Park et al., 2007, 2009a,b; Table 8). However, the increase of marbling of these cuts occurring with increasing $\mathrm{SW}$ is considered to be significant in terms of meat quality. The acceptability for these cuts does not change or increases to some extent with the increase of SW between 110 and $125 \mathrm{~kg}$. Collectively, the meat quality of fresh loin and ham does not change or improves slightly with increasing SW up to $125 \mathrm{~kg}$.

Fat and muscle color, aroma, and off-flavor of fresh belly may differ statistically between gilts and barrows or at different SW (Park et al., 2007, 2009a,b; Table 8), but such effects of the sex and SW are thought to be insignificant in terms of meat quality. The fat:lean ratio of the loin, referring to the relative area of total fat layers vs total muscle layers, is greater (Table 8) or tends to be greater
(Jeong et al., 2010) in barrows than in gilts, which is consistent with the relative fatness of the former vs latter. Similarly, this variable increases visibly between 110 and $125 \mathrm{~kg}$ of SW, although it does not increase further between 125 and $138 \mathrm{~kg}$ (Park et al., 2009a). The fat:lean balance of the loin, which is a measure for the appropriateness of the overall fatness of this primal, is an important quality criterion for this primal in Korea. This quality trait is not usually influenced by either sex or SW (Park et al., 2007, 2009a,b), but in the 2009a study of the workers, it improved significantly with the increase of SW between 110 and 125 $\mathrm{kg}$, but not between 125 and $138 \mathrm{~kg}$. The acceptability for this cut, however, was not affected by SW in any of the studies. Taken together, in Korea, the quality of fresh belly may or may not improve to some extent with the increase of SW up to 125 .

\section{Cooked pork}

Sensory characteristics of cooked loin and ham, including color, aroma, off-flavor, juiciness, and acceptability, are barely influenced by sex or SW in lean-type pigs (Cisneros et al., 1996; Leach et al., 1996; Kim et al., 2006; Jeong et al., 2010; Table 8). The tenderness of the loin was negatively correlated with SW with a low slope in Cisneros et al. (1996) among these studies, but this is partly attributable to a greater range of SW in this study (100 to $160 \mathrm{~kg}$ ) vs the others (110 to 138 or $140 \mathrm{~kg}$; Leach et al., 1996; Table 8). Sensory characteristics including taste of cooked belly, like those of cooked loin and ham, are uninfluenced by sex or SW. It is therefore apparent from these results that the eating quality of cooked pork is virtually uninfluenced by sex or SW.

\section{CONCLUSIONS}

An increase of the pig SW up to $140 \mathrm{~kg}$ does not cause any adverse effects on growth efficiency in lean-genotype finishers, but not in non-lean ones. Irrespective of the genotype for lean gain, the primary limiting factor in increasing SW is the carcass grading standard with respect to the carcass weight and fat content. In this regard, SW could be increased to some extent by using a low-energy diet and thereby reducing fat deposition. The redness and marbling of the muscle usually increase with increasing SW, which could result in an improvement of meat quality; other physicochemical 
and sensory characteristics of trimmed primal cuts are barely influenced by SW. Sensory quality traits or the eating quality of cooked pork also does not change with the increase of SW. As such, in some regions or countries including Korea, it is possible that the SW for lean pigs be lower than desirable because of the carcass grading criteria. If this is the case, the upper limits of the carcass weights imposed on higher yield grades may well be adjusted upward to fully take advantage of the high production efficiency of the lean-type finisher at higher BW.

\section{ACKNOWLEDGMENTS}

This work was supported in part by a 2009-2010 intramural research fund of the Regional Animal Industry Center at Gyeongnam National University of Science and Technology. Part of the content of this article was presented at the $14^{\text {th }}$ AAAP Animal Science Congress, Pingtung, Taiwan, August 23-27, 2010.

\section{REFERENCES}

Bonneau, M. and Lebret, B. 2010. Production systems and influence on eating quality of pork. Meat Sci. 84:293-300.

Chang, W. K. and Chung, S. K. 1985. Studies for improving swine feeding programs. Effects of L-lysine supplementation to grower feed. Annual Research Reports of National Livestock Research Institute, Republic of Korea, pp. 286-294.

Chung, C. Y., Chung, I. B., Kwon, D. J., Chung, S. K., Yoon, H. J. and Kim, K. S. 1981. Experiments on swine production. Effects of plane of nutrition and market weight on pork quality. Annual Research Reports of National Livestock Research Institute, Republic of Korea, pp. 436-476.

CIE. 1978. Recommendations on uniform color spaces-color difference equations, psychometric color terms. Supplement no. 2 to CIE Publication No. 15 (E-1.3.1) 1971/(TC-1-3). Commission Internationale de l'Eclairage, Paris.

Cisneros, F., Ellis, M., McKeith, F. K., McCaw, J. and Fernando, R. L. 1996. Influence of slaughter weight on growth and carcasscharacteristics, commercial cutting and curing yields, and meat quality of barrows and gilts from two genotypes. J. Anim. Sci. 74:925-933.

Corino, C., Musella, M. and Mourot, J. 2008. Influenceof extruded linseed on growth, carcass composition, and meat quality of slaughtered pigs at one hundred ten and one hundred sixty kilograms of liveweight. J. Anim. Sci. 86:1850-1860.
DARD. 2002. Increasing carcass weight. Pig Newsletter. Department of Agriculture and Rural Development. August, Hillsborough, Northern Ireland.

Fernandez-Duenas, D. M., Myers, A. J., Scramlin, S. M., Parks, C. W., Carr, S. N., Killefer, J. and McKeith, F. K. 2008. Carcass, meat quality, and sensory characteristics of heavy body weight pigs fed ractopamine hydrochloride (Paylean). J. Anim. Sci. 86:3544-3550.

Gu, Y., Schinckel, A. P. and Martin, T. G. 1992. Growth, development and carcass composition in five genotypes of swine. J. Anim. Sci. 70:1719-1729.

Ha, D.-M., Kim, G. D., Han, J.-C., Jeong, J. Y., Park, M.-J., Park, B.-C., Joo, S. T. and Lee, C. Y. 2010. Effects of dietary energy level on growth efficiency and carcass quality traits of finishing pigs. J. Anim. Sci. Technol. (Kor.) 52:191-198.

Huff-Lonergan E., Lonergan, S. M. and Beerman, D. H. 2003. Animal growth and meat quality. In Biology of Growth of Domestic Animals, C. G. Scanes (Ed.), Iowa State Press, Ames, IA, USA, pp. 220-232.

Jeong, J. Y., Park, B. C., Ha, D. M., Park, M. J., Joo, S. T. and Lee, C. Y. 2010. Effects of increasing slaughter weight on production efficiency and carcass quality of finishing gilts and barrows. Korean J. Food Sci. Anim. Resour. 30:206-215.

Joo, S. T., Kauffman, R. G., Kim, B. C. and Park, G. B. 1999.

The relationship of sarcoplasmic and myofibrillar protein solubility to colour and water-holding capacity in porcine longissimus muscle. Meat Sci. 52:291-297.

Kanis, E., Nieuwhof, G. J., de Greef, K. H., van der Hel, W., Vestergen, M. W. A., Huisman, J. and van der Wal, P. 1990. Effect of recombinant porcine somatotropin on growth and carcass quality in growing pigs: interactions with genotype, gender and slaughter weight. J. Anim. Sci. 68:1193-1200.

Kim, I. S., Jin, S.-K., Song, Y.-M., Park, K.-H., Kang, S.-M., Ha, J.-H., Kim, I.-J., Park, Y.-S. and Kim, J.-H. 2006. Quality characteristics of pork by sex of crossbred pigs. Korean J. Intl. Agri. 18:34-39

Kim, M. K., Park, J. S., Doh, C. H., Cho, W. J., Lee, S. D., Park, M. R. and Kim, W. S. 2009. A report on "A Survey on Current Status and Competitiveness of the Advanced Countries in Pig Production" (published in Korean; translated into English). Pork Checkoff Board, Korea Swine Association.

Kim, Y. S., Kim, S. W., Weaver, M. A. and Lee, C. Y. 2005. Increasing the pig market weight: world trends, expected consequences and practical considerations. Asian-Aus. J. Anim. Sci. 18:590-600. 
Latorre, M. A., Garcia-Belenguer, E. and Arino, L. 2008. The effects of sex and slaughter weight on growth performance and carcass traits of pigs intended for dry-cured ham from Teruel (Spain). J. Anim. Sci. 86:1933-1942.

Latorre, M. A., Lazaro, R., Valencia, D. G., Medel, P. and Mateos, G. G. 2004. The effects of gender and slaughter weight on the growth performance, carcass traits and meat quality characteristics of heavy pigs. J. Anim. Sci. 82:526-533.

Latorre, M. A., Ripoll, G., Garcia-Belenguer, E. and Arino, L. 2009. The increase of slaughter weight in gilts as a strategy to optimize the production of Spainish high quality dry-cured ham. J. Anim. Sci. 87:1464-1471.

Leach, L. M., Ellis, M., Sutton, D. S., McKeith, F. K. and Wilson, E. R. 1996. The growth performance, carcass characteristics, and meat quality of halothane carrier and negative pigs. J. Anim. Sci. 74:934-943.

Lee, C. Y., Lee, H. P., Lee, J. H. and Park, M. J. 2000. Effects of a low-energy diet on growth and carcass quality of finishing barrows. J. Agric. Tech. Res. Inst. (Jinju Natl. Univ., Republic of Korea) 13:199-205.

Lee, C. Y., Kim, M. H., Ha, D. M., Park, J. W., Oh, G. Y., Lee, J. R., Ha, Y. J. and Park, B. C. 2007. Effects of the energy level of the finisher diet on growth efficiency and carcass traits of 'high'-market weight pigs. J Anim. Sci. Technol. (Kor.) 49:471-480.

Lee, C. Y., Kwon, O. C., Ha, D. M., Shin, H. W., Lee, J. R., Ha, Y. J., Lee, J. H., Ha, S. H., Kim, W. K., Kim, W. K. and Kim, D. H. 2006. Growth efficiency, carcass quality characteristics and profitability of finishing pigs slaughtered at 130 vs. 110 kg. J. Anim. Sci. Technol. (Kor.) 48:493-502.

Lee, C. Y., Lee, H. P., Jeong, J. H., Baik, K. H., Jin, S. K., Lee, J. H. and Sohn, S. H. 2002. Effects of restricted feeding, low-energy diet, and implantation of trenbolone acetate plus estradiol on growth, carcass traits, and circulating concentrations of insulin-like growth factor (IGF)-I and IGF-binding protein-3 in finishing barrows. J. Anim. Sci. 80:84-93.

Leymaster, K. A. and Mersmann, H. J. 1991. Effect of limited feed intake on growth of subcutaneous adipose tissue layers and on carcass composition in swine. J. Anim. Sci. 69: 2837-2843.

MIFAFF. 2007. "Grading Standards for Livestock Products" (published in Korean; translated into English). Notification No. 2007-40 of the Ministry of Food, Agriculture, Forestry and Fisheries, Republic of Korea.

Martin, A. H., Sather, A. P., Fredeen, H. T. and Jolly, R. W. 1980. Alternative market weights for swine. II. Carcass composition and meat quality. J. Anim. Sci. 50:699-705.

MLC. 2003. An Industry Guide to Production of Heavier Pigs. Meat andLivestock Commission. Milton Keynes, U.K.

NASS. 2006. Agricultural Statistics. USDA. National Agricultural Statistics Service. US Government Printing Office, Washing, D.C.

Neely, J. D., Johnson, R. K. and Walters, L. E. 1979. Efficiency of gains and carcass characteristics of swine of two degrees of fatness slaughtered at three weights. J. Anim. Sci. 48:10491056.

NRC. 1998. Nutrient Requirements of Swine. $10^{\text {th }}$ ed. National Academy Press, Washington, D.C.

Park, M. J. 2010. Feasibility of increasing the pig market weight: effects of market weight and dietary energy level on the productivity and carcass quality traits of finishing pig. Ph.D. Dissertation, Gyeongsang National University, Jinju, Korea.

Park, M. J., Ha, D. M., Shin, H. W., Lee, S. H., Kim, W. K., Ha, S. H., Yang, H. S., Jeong, J. Y., Joo, S. T. and Lee, C. Y. 2007. Growth efficiency, carcass quality characteristics and profitability of 'high'-market weight pigs. J. Anim. Sci. Technol. (Kor.) 49:459-470.

Park, M. J., Jeong, J. Y., Ha, D. M., Park, J. W., Sim, T. G., Yang, H. S., Lee, C. Y., Joo, S. T. and Park, B. C. 2009a. Relationships of the slaughter weight to growth performance and meat quality traits in finishing pigs fed a low-energy diet. J. Anim. Sci. Techonl. (Kor.) 51:135-142.

Park, M. J., Jeong, J. Y., Ha, D. M., Han, J. C., Sim, T. G., Park, B. C., Park, G. B., Joo, S. T. and Lee, C. Y. 2009 b. Effects of dietary energy level and slaughter weight on growth performance and grades and quality traits of the carcass in finishing pigs. J. Anim. Sci. Techonl. (Kor.) 51:143-154.

Piao, J. R., Tian, J. Z., Kim, B. G., Choi, Y. I., Kim, Y. Y. and Han, I. K. 2004. Effects of sex and market weight on performance, carcass characteristics and pork quality of market hogs. Asian-Aus. J. Anim. Sci. 17:1452-1458.

Ryu, Y. C. and Kim, B. C. 2005. The relationship between muscle fiber characteristics, postmortem metabolic rate, and meat quality of pig longissimus dorsi muscle. Meat Sci. 71: 351-357.

SAS. 1996. SAS User's Guide: Statistics. SAS Inst., Inc., Cary, NC, USA.

Schinckel, A. P., Mahan, D. C., Wiseman, T. G. and Einstein, M. E. 2008. Growth of protein, moisture, lipid, and ash of two genetic lines of barrows and gilts from twenty to one hundred twenty-five kilograms of body weight. J. Anim. Sci. 86:460471. 
Unruh, J. A., Friesen, K. G., Stuewe, S. R., Dunn, B. L., Nelssen, J. L., Goodband, R. D. and Tokach, M. D. 1996. The influence of genotype, sex, and dietary lysine on pork subprimal cut yields and carcass quality of pigs fed to either 104 or 127 kilograms. J. Anim. Sci. 74:1274-1283.

Warner, R. D., Kauffman, R. G. and Greaser, M. L. 1997. Muscle protein changes post mortemin relation to pork quality traits.
Meat Sci. 45:339-352.

Wiseman, T. G., Mahan, D. C., Peters, J. C., Fastinger, N. D., Ching, S. and Kim, Y. Y. 2007. Tissue weights and body composition of two genetic lines of barrows and gilts from twenty to one hundred twenty-five kilograms of body weight. J. Anim. Sci. 85:1825-1835.

(Received Mar. 14, 2011; Revised Apr. 20, 2011; Accepted May 6, 2011) 